\title{
Spiritual Dimensions in Leadership: A Comparative Analysis of Polish and Bhutanese Managers
}

\author{
Joanna Samul (D) \\ Wangmo ${ }^{2}$ \\ 'Department of Management, Economy \\ and Finance, The Faculty of Engineering \\ Management, Bialystok University of \\ Technology, Bialystok, Poland; \\ ${ }^{2}$ Department of Humanities \& \\ Management, Jigme Namgyel Engineering \\ College, Dewathang, Bhutan
}

Correspondence: Joanna Samul Department of Management, Economy and Finance, The Faculty of Engineering Management, Bialystok University of Technology, 45A, Wiejska Street,

Bialystok, I5-35I, Poland

Tel +48506I89557

Email j.samul@pb.edu.pl
Purpose: This study examined the effects of vision, calling and membership on organizational commitment and performance in the Asian and European context, which according to our knowledge has not been sufficiently employed previously. Firstly, by drawing on the spiritual leadership concept, the differences between leaders' spirituality in Poland and Bhutan were examined. Secondly, the relationships between the constructs: vision, calling, membership, organizational commitment and performance of both Polish and Bhutanese managers were studied.

Methods: This study adopted the spiritual leadership scale proposed by Fry. The data used in this study were gathered through a survey of 194 managers. The confirmatory factor analysis (CFA) and the path coefficient were applied in the study.

Results: By comparing spiritual dimensions of leadership, the study demonstrated positive and significant relationships between the constructs that influence each other in various ways. The study indicates that the strength of the influence of specific dimensions depends on the perception of their significance for managers due to the cultural context.

Conclusion: The study contributed to the literature by examining the dimensions of spiritual leadership that are endorsed differently by the Polish and the Bhutanese managers. The findings shed light on the creation of a positive work environment by managers in which employees can feel appreciated and fulfilled.

Keywords: spiritual leadership, membership, calling, commitment, performance

\section{Introduction}

The role of a modern leader is to take care of himself/herself, the employees he/she manages and the organization. ${ }^{2}$ Who a leader is, determines how the leader manages others. A leader should have an inner calmness to enable employees to gain clarity, to inspire trustworthiness via authenticity and strengthen their hope for a better future. 3,4 A leader should "see others", which means pay attention to the needs and interests of employees he/she manages and take care of their wellbeing. ${ }^{5,6}$ A leader should also integrate various viewpoints - his/her own, employees' own and organizational perspectives, and look out for an integrated solution. ${ }^{4}$ A leader without integrative awareness and driven by fear is ineffective. ${ }^{7}$ The current situation characterized by the fear of the unknown is challenging for leaders and demands a new leadership approach based more on vision, values and relationships. ${ }^{8,9}$

The need to shift to spiritual values represented by a leader can be in light of these challenges. A spiritual leader should be like a "spiritual anchor" - a model of deeply entrenched spiritual motives, values, and attitudes which might be used to 
shape an individual's behaviour, to recognize the meaning of work, create a vision, appreciate efforts of the colleagues, and enable the expression and identification of the values that underpin the organization. ${ }^{10}$

Many researches have confirmed the positive impact of spiritual leadership on employees' meaningful work and a sense of membership in the organization, commitment, and organizational outcome such as performance. ${ }^{11-16}$ However, there is insufficient studies that have explored the dimensions of spiritual leadership and compared European and Asian leaders. Spiritual leadership has been examined in various national contexts but in separate studies (eg China, South Korea, Malaysia or Turkey). ${ }^{17-20}$ It is worth to noted that there is a lack of research about spiritual leadership from Poland and Bhutan, although there is a need for more empirical studies from different countries. ${ }^{21,22}$ Moreover, there are few studies from European countries. ${ }^{21}$ There is also the need to take a closer look at spiritual leadership from different cultures and to conduct comparative analyses through cross-national studies. ${ }^{21-23}$ The impact of cultural context cannot be ignored when exploring employees' behaviour. ${ }^{24}$ Therefore, the current research on a sample of Polish and Bhutanese leaders could add new value to the concept of spiritual leadership. New results are needed to understanding a cultural context when exploring leadership that in different cultures "has to account for philosophical assumptions and frames of reference underpinning those cultures". ${ }^{25,26}$ Moreover, there is a need for more studies on different antecedents of spiritual leadership. ${ }^{21}$ The cultural context that includes beliefs, values and approach to work can be that antecedent.

Therefore, the aim of this paper was to compare the spiritual dimensions of leadership between Polish and Bhutanese managers. The choice of these two countries for research was dictated by the fact that they are representatives of different cultures - European and Asian. Differences in both European and Asian cultures and their connections with beliefs, values and perspectives may have implications for leadership spirituality. Xing claimed that leaders' beliefs and values are always reflected in their behaviours. ${ }^{27}$

The arousal of interest in Bhutan was awakened due to the fact that it is one of the most peaceful countries in the world and the gross national happiness is a measure of the domestic well-being over the Gross National Product. ${ }^{28,29}$ Bhutan's constitution with Mahayana Buddhism as the state religion "promotes the principles and values of peace, non-violence, compassion and tolerance", as the "spiritual heritage" of Bhutan. ${ }^{30}$ Bhutan as an example of an Asian country with collective culture characterizes by a strong sense of belonging and a spiritual connection with the others. ${ }^{31}$ According to the Asian perspective, spirituality is an inborn part of being human and it means a connection with nature and other subjects. Meanwhile, in European culture as in Poland, employees try to be neutral in terms of religion, they work using mainly the brain and pay less attention to the heart and the soul. ${ }^{32} \mathrm{An}$ European materialistic worldview has become the dominant pattern of life today and it is deeply non-spiritual. ${ }^{32} \mathrm{In}$ contrast with collectivist cultures, individualistic cultures pay attention on self-sufficiency, individual goals, and a deriving of satisfaction from one's own accomplishments. ${ }^{33}$ Therefore, we can expect that individualist cultures probably will focus more on effectiveness of spiritual leadership. The article is an attempt to shed a light on the approach to spiritual leadership by managers from Asian and European cultures.

The current research makes three contributions to the extant literature. Firstly, it attempts discussions on the dimensions of spiritual leadership in the cultural context, thereby enriching the literature on that topic. Secondly, it compared the leadership spirituality among the Polish and the Bhutanese managers, which fills the research gap in these countries, additionally in a comparative context as representatives of European and Asian countries. Thirdly, the study explores the effects of managers' vision on organizational commitment and performance. Additionally, the possible mediating effects of calling and memberships on the relationship between vision and organizational commitment and performance of both the Bhutanese and the Polish leaders. The results of the research provide theoretical and practical values.

\section{Literature Review and Hypotheses Development}

The initial research on the concept of spiritual leadership in the workplace comes from Fry who indicated three main dimensions of the construct: (a) values, attitudes, and behaviours of spiritual leaders (vision, hope/faith, and altruistic love) that meet the needs of both leaders and employees' (b) spiritual well-being (calling and membership) and influence (c) organizational outcomes (organizational commitment and productivity). ${ }^{1,34}$ Many 
researches have confirmed the causal relationships of these dimensions for their universal applications. ${ }^{1,35-37}$ However, there are no sufficient studies that compared spiritual leadership in the eastern and western context.

The first dimension includes a vision that is described as a future direction of the organization and explains the reasons for taking that direction, meanwhile, hope and faith with altruistic love enhances the view that the organization's vision will be achieved. ${ }^{1}$ The role of every leader, not only spiritual leaders, is to set visions and goals and clearly communicate the true meaning of the visions. Vision defined as "future images of the collective" is an important part of an effective leader. ${ }^{38-40}$ Hybels claimed that "vision is the fuel that leaders run on". Spiritual leaders focus on inspiring employees to achieve organizations' vision by providing support, appreciating and fostering a sense of belonging. ${ }^{34}$ Employees are more likely to identify with those visions that make their tasks significant to them personally and to the organization. This makes employees see their tasks as special and meaningful. ${ }^{12}$ Consequently, they will be more intrinsically motivated and actively engaged in searching for new solutions or creating diverse ideas in order to achieve the organization's vision more efficiently. ${ }^{42,43}$ It can be said that spiritual leaders provide the direction, the way and the purpose.

Many studies have confirmed that sharing vision among leaders and members is essential for organizational outcomes. ${ }^{38-40,44}$ The goal of spiritual leadership is to establish a shared organizational vision and thereby enhance the organization's commitment and performance. $^{11,45}$ A spiritual leader delivers a common and clear vision both spirituality-grounded vision and the process of creating a vision for employees, which causes employees to more likely perform better. ${ }^{46} \mathrm{~A}$ spiritual leader inspires followers to display their tenacity and pursue excellent performance by doing their best to take on challenging tasks. Visions are related to the collective identity of employees, showing them who they can become collectively in the future. ${ }^{38}$

Moreover, a shared vision contributes to outstanding leadership across different cultures. ${ }^{47}$ Collectivism/individualism are considered important to understand leadership. ${ }^{48,49}$ Collective culture is more common in eastern countries than in western countries. Collective culture has a stronger acceptance and respect for authority, which may cause spiritual leaders to be more effective in this culture. Therefore in a collectivist culture, employees tend to work more for their leader, even though it does not provide a personal benefit to them, and even though it contradicts their personal objectives. ${ }^{50,51}$ In individualist cultures, the individual's personal relationship with the leaders and the benefits of this relationship depends on the individual's personal objectives. ${ }^{52}$ Moreover, the longterm orientation, which is related to the development of virtues that will benefit someone in the future, is also more common in Asian culture than in European culture. ${ }^{32}$ Thus, it can be suggested that leaders' vision might be more important for collectivist cultures than individualistic culture.

The second dimension is spiritual well-being described by calling and membership. Calling is the feeling that the life of an individual is meaningful, valuable, and capable of great achievements. ${ }^{1}$ In the context of organization calling, it means a sense of meaning and purpose of work. When a leader causes the employees to feel that their job and lives are special and meaningful, it results in membership. ${ }^{12}$ Membership is the feeling of being understood and appreciated in interrelationships and in social interactions. ${ }^{1}$ Membership involves establishing an organizational culture based on the fact that the leaders and employees have genuine care and appreciation for themselves and others, thereby producing a sense of membership. ${ }^{34}$ A sense of being understood and appreciated is man's most fundamental need. Appreciation may help employees feel valued, unleashing their intrinsic motivation and desire to excel. ${ }^{53}$ Having a sense of being understood and appreciated is largely a matter of interrelationship and connection through social interaction and thus membership. ${ }^{54}$ People with membership have an awareness of being a part of a community and are connected to others at work. The important sources of meaningful work are values and standards found in group norms and organizational policies. Leaders as individuals who create organizational culture have significant influences on a sense of calling and membership. Viewing work as a calling is related to goal-directed behaviours at work and higher organizational attachment. ${ }^{55,56}$ Leaders who promote calling and membership by creating a vision, also support the development of organizational commitment and financial performance. ${ }^{57}$

Culture differentiations are related to various dimensions of spiritual leadership. ${ }^{50,58,59}$ Individualismcollectivism defines how an individual sees himself/herself within the community. ${ }^{60}$ In western culture, employees tend to see themselves as independent from others. 
Meanwhile, eastern culture is more prone to defining themselves as dependent on others, highlighting compatibility with the collective interests. ${ }^{51}$ They tend to believe that their leader's interest reflects the interest of the collective individuals. ${ }^{61}$ Therefore, it is suggested that the relationship of spiritual leadership with membership is expected to be stronger in countries with collectivist cultures. Additionally, in general, the Bhutanese not only work with hands but also work with their hearts and spirit, which cause them to discover the significance and purpose of work.

Based on the above analysis, the following hypotheses are therefore proposed:

H1. A vision will have a more positive effect on organizational commitment and performance among Bhutanese managers than Polish managers.

H2a. Membership will mediate the relationships between vision and organizational commitment more among Bhutanese managers than Polish managers.

H2b. Membership will mediate the relationships between vision and performance more among Bhutanese managers than Polish managers.

H3a. Calling will mediate the relationships between vision and organizational commitment more among Bhutanese managers than Polish managers.

H3b. Calling will mediate the relationships between vision and performance more among Bhutanese managers than Polish managers.

\section{Method}

\section{Procedure and Sample}

The data used in this study were gathered through a survey from managers. The research is a non-interventional study and ethical approval is not required, only compliance with the rules of ethics because of national laws on ethical principles in the field of management sciences. ${ }^{62,63}$ The survey was anonymous and did not contain sensitive data enabling the person to be identified. Additionally, the data was processed and presented collectively with coding. The participant was informed about the aim of the research and the collection of the data and gave voluntary consent to participate in the study.

The participants worked in various companies located in Poland and Bhutan. The authors visited different companies to present the aim of the study and encouraged managers to participate. A convenience sample was used in the study because of the impossibility to conduct research on respondents from the entire population. ${ }^{64}$ The participants were allowed to fill the survey by using a self-administered paperand-pencil questionnaire or online questionnaire. The use of a specific questionnaire was related to the convenience of the respondents. The questionnaire included two parts, spiritual leadership questions and the characteristics of respondents including gender, age, experiences and level of management. The research applied similar samples to collect international data within the same timeframe (from September to December, 2019). Out of 300 distributed surveys, 194 were returned. In total, we obtained 65 paper-and-pencil questionnaires and 129 online questionnaires. Consequently, 169 questionnaires from Poland and 125 questionnaires from Bhutan were thus employed for data analysis, with a response rate of $64 \%$. The sample size has a significant effect on accomplishing statistical significance. Table 1 presents the respondents' profiles.

\section{Instrument}

This study adopted the spiritual leadership scale created by Fry et al. ${ }^{1}$ This model is "the most robust framework for spiritual leadership". ${ }^{21}$ The model measures the scales through several statements, for example, vision was measured with 4 items like: "I understand and I am committed to my organization's vision"; membership with 4 items like: "I feel my organization appreciates me and my work"; calling with 4 items like: "The work I do is meaningful to me"; organizational commitment

Table I Comparison Between the Polish and the Bhutanese Sample

\begin{tabular}{|l|l|c|c|}
\hline \multicolumn{2}{|l|}{ Characteristics } & $\begin{array}{c}\text { Polish } \\
\text { Managers } \\
\text { (n= 169) }\end{array}$ & $\begin{array}{c}\text { Bhutanese } \\
\text { Managers } \\
(n=125)\end{array}$ \\
\hline Gender & Male & $98(58 \%)$ & $85(68 \%)$ \\
& Female & $71(42 \%)$ & $40(32 \%)$ \\
\hline Age group & Under 30 years & $37(22 \%)$ & $25(20 \%)$ \\
& $31-50$ years & $108(64 \%)$ & $95(76 \%)$ \\
& Above 5I & $24(14 \%)$ & $5(4 \%)$ \\
\hline \multirow{2}{*}{ Experiences } & Under I year & $7(4 \%)$ & $5(4 \%)$ \\
& I-5 years & $44(26 \%)$ & $10(8 \%)$ \\
& $5-10$ years & $47(28 \%)$ & $30(24 \%)$ \\
& I0-I5 years & $20(12 \%)$ & $25(20 \%)$ \\
& Above I5 years & $51(30 \%)$ & $55(44 \%)$ \\
\hline Level of & Low level & $54(32 \%)$ & $35(28 \%)$ \\
management & Middle level & $86(51 \%)$ & $70(56 \%)$ \\
& Top level & $29(17 \%)$ & $20(16 \%)$ \\
\hline
\end{tabular}


with 5 items like: "I feel like 'part of the family' in this organization"; performance with 4 items like: "In my department, everyone gives his/her best efforts" according to the original Fry's model. The responses were on a 5-point Likert scale, with 0 as "strongly disagree" and 4 as "strongly agree".

\section{Data Analysis}

Descriptive statistics (mean and standard deviation) were calculated for spiritual leadership. To examine the accuracy of the model, the reliability and validity of the variables were measured as well as running convergent validity and discriminant validity. The average variance extracted (AVE) and the composite reliability (CR) were calculated in order to determine the convergent validity which measures multiple items of the same concept. ${ }^{65}$ Discriminant validity were determined by the estimated correlations using the Spearman rho correlation coefficient among all construct pairs. Cronbach's coefficient alphas were calculated to determine the internal consistency and scale reliability. Cronbach's alpha is a statistics that demonstrates that tests and scales that were constructed or adopted for research projects are fit for the purpose. ${ }^{66}$ The confirmatory factor analysis (CFA) as a widely adopted method was employed by SPSS AMOS program. ${ }^{67}$ The chi-square value, degree of freedom, root mean square error approximation (RMSEA), normed fit index (NFI), comparative fit index (CFI), incremental fit index (IFI), and Tucker-Lewis index (TLI) to test the validity of the constructs were applied in this study. The path coefficient was also applied in the study.

\section{Results}

\section{Descriptive Statistics and Construct Validity}

The mean, standard deviations and correlations have been shown in Table 2. The mean scores for each spiritual leadership item ranged from 2.77 to 2.97 in Poland and 2.54 to 3.26 in Bhutan. Yet both the Polish and the Bhutanese managers agreed with the meaning of an organization's vision as a leader's attitude. In the Polish samples, calling (mean=2.92, $\mathrm{SD}=0.90)$ and membership (mean=2.93, $\mathrm{SD}=0.99$ ) in spiritual well-being were assessed quite similarly. In the Bhutanese sample, calling was rated clearly higher $($ mean $=3.26, \mathrm{SD}=0.78)$ than membership (mean=2.92, $\mathrm{SD}=0.90)$. Moreover, calling appeared to be the most emphasized dimension by the Bhutanese managers, whereas membership was rated the lowest of all dimensions. In the case of organizational outcomes, the Polish managers rated organizational commitment (mean=2.77, $\mathrm{SD}=0.99$ ) lower than the Bhutanese managers (mean=3.09, $\mathrm{SD}=0.86$ ). Performance was rated on a similar level by both the Polish $($ mean $=2.97$, $\mathrm{SD}=0.79$ ) and the Bhutanese managers (mean=2.96, $\mathrm{SD}=0.77)$. However, in the Polish samples, performance was the highest-rated dimension of spiritual leadership, whereas it was rated at an average level in the Bhutanese samples.

Discriminant validity can be examined in different ways. In this study, the estimated correlations between all construct pairs were determined and it has been presented in Table 2. The results of Spearman correlations between all construct pairs were positive and significant $(\mathrm{p}<0.01, \mathrm{p}<0.05)$, providing evidence of discriminant validity. Specifically, vision was very strongly associated with commitment $\left(r_{s}=0.86, p<0.01\right)$ and calling $\left(r_{s}=0.80\right.$, $\mathrm{p}<0.01)$ in the case of Poland and also with commitment $\left(r_{s}=0.74, p<0.01\right)$ and performance $\left(r_{s}=0.71, p<0.01\right)$ in the case of Bhutan. Moreover, it can be observed that in the Polish samples, the correlations were from moderate (ie $r_{s}$ $=0.56)$ to strong $\left(r_{\mathrm{s}}=86\right)$ and in the Bhutanese samples, the correlations were from weak $\left(r_{s}=21\right)$ to strong $\left(r_{s}=0.74\right) .{ }^{68}$

Table 2 Means, Standard Deviations and Correlations of Dimensions of Spiritual Leadership from the Polish and the Bhutanese Samples

\begin{tabular}{|c|c|c|c|c|c|c|c|c|c|c|c|c|c|c|}
\hline \multirow[t]{2}{*}{ Dimension } & \multicolumn{7}{|c|}{ Poland } & \multicolumn{7}{|c|}{ Bhutan } \\
\hline & $\mathbf{M}$ & SD & I & 2 & 3 & 4 & 5 & $\mathbf{M}$ & SD & I & 2 & 3 & 4 & 5 \\
\hline I.Vision & 2.84 & 0.98 & - & 0.80 & 0.68 & 0.86 & 0.75 & 2.98 & 0.80 & - & 0.38 & $0.42^{*}$ & 0.74 & 0.71 \\
\hline 2.Calling & 2.92 & 0.90 & & - & 0.71 & 0.79 & 0.71 & 3.26 & 0.78 & & - & $0.23 *$ & $0.34 *$ & $0.22^{*}$ \\
\hline 3.Membership & 2.93 & 0.99 & & & - & 0.78 & 0.59 & 2.54 & 0.96 & & & - & 0.65 & $0.2 I^{*}$ \\
\hline 4. Commitment & 2.77 & 0.99 & & & & - & 0.68 & 3.09 & 0.86 & & & & - & 0.68 \\
\hline 5.Performance & 2.97 & 0.79 & & & & & - & 2.96 & 0.77 & & & & & - \\
\hline
\end{tabular}

Note: $p<0.01,{ }^{*} p<0.05$.

Abbreviation: $M$, mean; SD, standard deviations. 
Table 3 Construct Validity Dimensions of Spiritual Leadership from the Polish and the Bhutanese Samples

\begin{tabular}{|l|c|c|c|c|c|c|}
\hline \multirow{2}{*}{ Dimension } & \multicolumn{3}{|c|}{ Poland } & \multicolumn{3}{c|}{ Bhutan } \\
\cline { 2 - 7 } & $\boldsymbol{\alpha}$ & AVE & CR & $\boldsymbol{\alpha}$ & AVE & CR \\
\hline Vision & 0.83 & 0.61 & 0.82 & 0.76 & 0.51 & 0.75 \\
Calling & 0.77 & 0.54 & 0.82 & 0.59 & 0.56 & 0.79 \\
Membership & 0.89 & 0.69 & 0.90 & 0.88 & 0.51 & 0.70 \\
Commitment & 0.88 & 0.70 & 0.92 & 0.88 & 0.64 & 0.89 \\
Performance & 0.74 & 0.49 & 0.73 & 0.80 & 0.52 & 0.73 \\
\hline
\end{tabular}

Note: $\mathrm{p}<0.01$.

Abbreviations: $\alpha$, Cronbach alpha coefficient; AVE, average variance extracted; $\mathrm{CR}$, composite reliability.

The strong correlations may be due to the fact that the individual dimensions of spiritual leadership are more related to each other in the case of the Polish sample than in the Bhutanese sample.

Table 3 shows the internal consistency measured by the Cronbach alpha coefficient and convergent validity by the $\mathrm{CR}$ and AVE. The results obtained indicate that the reliability was greater than the recommended value $(\alpha>0.70)$ for all dimensions of the Polish samples and for four dimensions of the Bhutanese samples (except calling, $\alpha=0.58$ ). ${ }^{69,70}$ The convergent validity as a degree that measures multiple items of the same concept usually is measured by the average variance extracted and the composite reliability. ${ }^{65}$ The CR were all higher than 0.6 , and the AVE was also greater than 0.5 according to the literature (AVE $=0.49$ for performance in the Polish sample is slightly below) ${ }^{71}$ Hence, all criteria of the evaluated model were supported for its measures' reliability and validity.

\section{Confirmatory Factor Analysis and Hypotheses Testing}

The results of the CFA models are shown in Table 4. The fit indices for both the Polish and the Bhutanese models were greater than the recommended value $(\mathrm{CFI}=0.941 / 0.924$, $\mathrm{NFI}=0.912 / 0.902$, IFI $=0.955 / 0.934)$. The conventional cutoff for these indices is 0.90 for good fitting models. ${ }^{71}$ The RMSEA of 0.069 and 0.077 is slightly below 0.08 , thus it is acceptable. ${ }^{72}$ The ratio of chi-square and degree of freedom were 2.36 and 2.50 , ranging between 1 and 3 , respectively. The chi-square test depends on the size of a model that is quite small in both the Polish and the Bhutanese sample. ${ }^{73}$

Figure 1 shows the standardized path coefficients for the Polish and the Bhutanese samples. All of the standardized path coefficients were significant $(p<0.01)$. The structural model results indicated that a vision of spiritual leadership has a positive direct effect on commitment $(\beta=0.28, \mathrm{p}<0.01)$ and performance $(\beta=0.069, \mathrm{p}<0.01)$ for the Polish sample. For the Bhutanese sample, vision has a higher effect on commitment $(\beta=0.42, p<0.01)$ and performance $(\beta=0.91$, $\mathrm{p}<0.01)$ and this supports H1. It can be noticed that vision has a more positive impact on performance than commitment. However, it seems quite common because vision, in short, is setting a future direction with strategy, goals and objectives. Thus, vision determines the organizational results that employees should strive for.

The relationships between vision and commitment and performance through calling and membership are positive and significant $(p<0.01)$. However, it can be seen that standard indirectly affects vision on commitment and performance through membership in the case of the Polish samples: $0.2(0.8 \times 0.25)$ for commitment and 0.04 $(0.8 \times 0.05)$ for performance, meanwhile, in the case of the Bhutanese samples they are $0.09(0.6 \times 0.16)$ and 0.25 (0.6x0.42), respectively. This means that membership mediates more the relationships between vision and organizational commitment among the Polish managers than among the Bhutanese managers, which does not confirm hypothesis $2 \mathrm{a}$. However, membership mediates more, the relationships between vision and performance among the Bhutanese managers than among the Polish managers which agrees with hypothesis $2 b$.

It can be noticed that standard indirectly affects vision on commitment and performance through calling in the case of the Polish samples, respectively: $0.22(0.97 \times 0.23)$ and $0.19(0.97 \times 0.2)$, meanwhile in the case of the Bhutanese samples, they are $0.01(0.67 \times 0.02)$ and 0.24 $(0.67 \times 0.37)$. The results indicate that calling mediates

Table 4 CFA Results for the Polish and the Bhutanese Samples

\begin{tabular}{|l|c|c|c|c|c|c|c|c|}
\hline & $\chi^{2}$ & df & $\chi^{2} / \mathbf{d f}$ & CFI & NFI & IFI & TLI & RMSEA \\
\hline Model for the Polish sample & 429.9 & 182 & 2.36 & 0.941 & 0.912 & 0.955 & 0.951 & 0.069 \\
Model for the Bhutanese sample & 1238.2 & 495 & 2.50 & 0.924 & 0.902 & 0.934 & 0.931 & 0.077 \\
\hline
\end{tabular}

Abbreviations: $\chi^{2}$, chi-square value; df, degree of freedom; CFI, comparative fit index; NFI, normed fit index; IFI, incremental fit index; TLI, Tucker-Lewis index; RMSEA, root mean square error approximation. 


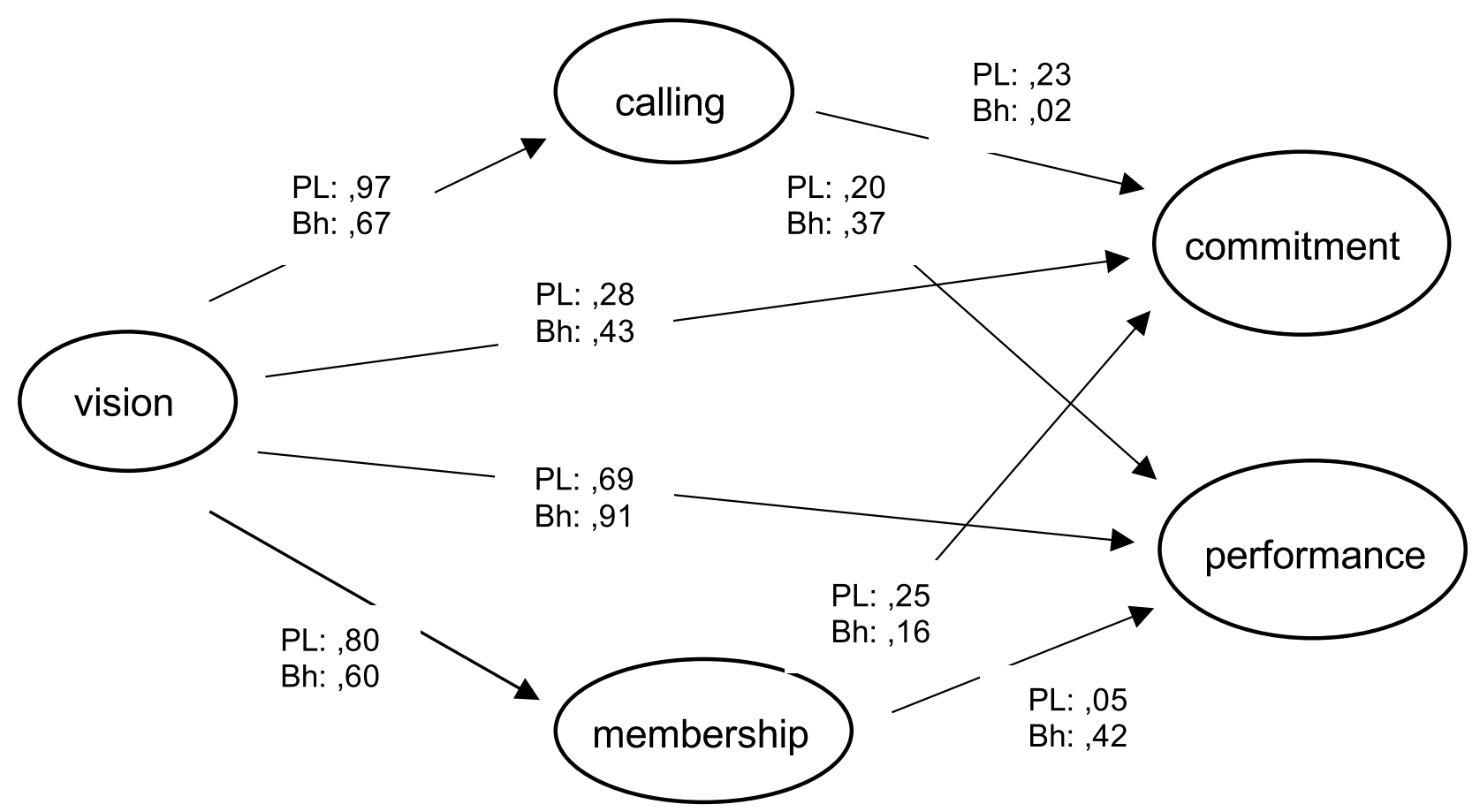

Figure I Path coefficient results within Poland (PL) and Bhutan (Bh) samples.

Note: $p<0.01$.

Abbreviations: PL, $\beta$ for Polish sample; Bh, $\beta$ for Bhutanese sample.

more, the relationships between vision and organizational commitment among the Polish managers than among the Bhutanese managers and this does not agree with hypothesis 3a. The results obtained also indicate that calling slightly mediates more, the relationships between vision and performance among the Bhutanese leaders than among the Polish leaders. Although the difference (0.19 and 0.24) is very small, it agrees with hypothesis $3 b$.

\section{Discussion}

We explore the dimensions of spiritual leadership in the Asian and the European context, which has not been sufficiently employed previously. The study examined the effects of vision, calling and membership on organizational commitment and performance. The study made a contribution to the literature by examining the dimensions of spiritual leadership that are endorsed differently by Polish and Bhutanese managers. Our results provide additional understanding of the literature of spiritual leadership within the cultural context.

Firstly, the study confirmed the positive and significant relationships between the three constructs of spiritual leadership - vision, spiritual well-being such as calling and membership and organizational outcomes such as commitment and performance. The findings confirm the significance of spiritual dimensions for managers. Although these relationships were well-explored in many previous studies, there is not any such research from Poland and Bhutan. Our study provides empirical evidence that spiritual leadership has a positive impact on organizational outcomes. It is very important especially in the case of Poland because there is much more research from Asian countries than from European countries. This shows that Polish managers as a representative of European managers also pay attention to spiritual value.

Secondly, the study contributed by presenting an approach to the dimensions of spiritual leadership from Poland as an example of a country with western culture and from Bhutan as an example of a country with eastern culture. The results obtained show that particular dimensions of spiritual leadership were assessed quite high with slight differences. Performance was rated as the highest dimension by Polish managers. The study confirmed that managers from western individualistic culture are more focused on results individual or organizational. The highest difference was between the membership dimensions. Moreover, membership was assessed as the lowest among all dimensions by the Bhutanese managers. This may mean that the Bhutanese managers do not pay much attention to membership. It can be the result of a collective culture where membership is 
natural and has always existed. It is a strong part of the Asian culture that may not be even considered as a separate and significant dimension because it is almost "obligatory". The results supported to some degree, convergence and to some degree, divergence in perceived dimensions of spiritual leadership across European and Asian contexts. The findings show, on the other hand, that there are discrepancies in the perception and meaning of spiritual dimensions between Polish and Bhutanese samples. This suggests that cultural context might be an antecedent of spiritual leadership behavior. On the other hand, by the confirmation of the positive relationships among the studied constructs, the findings show the significance of leaders spirituality, regardless of the cultural context. This shows that spiritual dimensions of leadership are important for leaders across the culture. Therefore, we can consider the spiritual leadership model as a universal leadership concept.

Thirdly, the study presented the mediating effects of vision through calling and membership on commitment and performance. This can be of aid for managers to better understand the importance of the meaning and a sense of being a member of their organizations to further increase organizational outcomes. It was observed that calling and membership mediated more, the relationships between vision and performance among the Bhutanese managers than among the Polish managers. Meanwhile, the spiritual dimensions of well-being mediated more, the relationships between vision and commitment among the Polish managers than among the Bhutanese managers. These results show that calling and membership mediated these relationships but in different ways. This is very interesting because calling and membership dimensions mainly affect the Bhutanese managers' performances which are not seen by them as significantly important and on the commitment of the Polish managers which was also rated as the lowest dimension. This can mean that the less assessed the dimension, the more significant the effect of that dimension on another is. The study indicates that the strength of the influence of specific dimensions depends on the perception of their significance for managers due to the cultural context.

The findings provide also suggestions for organizational behavior. All the dimensions of spiritual leadership are important for managers, which subsequently will lead to creating a positive work environment based on spiritual values like being understood and appreciated in interrelationships in order to achieve employee and organizational outcomes. This means that managers in organizations need to understand the significance of vision, calling, membership in acquiring commitment and in achieving goals. Organizations need to create a work environment for developing spirituality by leaders.

\section{Conclusions and Limitations}

The study provides analyses through cross-national studies and explored the dimensions of spiritual leadership in the sample of European and Asian context. The results obtained show the positive and significant correlation between vision and commitment and performance, and the mediating role of calling and membership among the studied constructs in both the Polish and the Bhutanese managers. The findings indicate that there are certain differences between the Polish and the Bhutanese managers in the approach to spiritual leadership. The particular constructs interacted with each other in different ways. This might be related to the cultural context. This is important for global organizations, as well as for national organizations whose managers are grounded in cultures and embrace spirituality to their work differently.

Despite contributing the advances to the spiritual leadership theory, the present study also has limitations. Firstly, the study's data were confined to a sample of the two countries: Poland and Bhutan. This means that the findings cannot be generalized across the general population of cultural contexts. However, the research sheds light that there may be differences in the application of the spiritual leadership model due to cultural factors. This leads to the second limitation. The study has a limited scope because this did not examine the relationships between cultural contingencies and specific spiritual leadership. Additionally, the study did not include respondents' demographic characteristics, which could allow for the understanding of the measurement differences. Next, the sample of the study was not large, thus it limits the generalization across the general population. Finally, it is not possible to compare the results of the research with other findings, because there are not such cross-national studies. However, these limitations indicate further directions of research.

\section{Disclosure}

The authors report no conflicts of interest in this work.

\section{References}

1. Fry LW, Vitucci S, Cedillo M, et al. Spiritual leadership and army transformation: theory, measurement, and establishing a baseline. Leadersh Q Spec Issue Spiritual Leadersh. 2005;16:807-833. 
2. Yawson R. Strategic flexibility analysis of HRD research and practice post COVID-19 pandemic. Hum Resource Dev Int. 2020;23 (4):406-417. doi:10.1080/13678868.2020.1779169

3. Ronthy M. Leader Intelligence: How You Can Develop Your Leader Intelligence with the Help of Your Soul, Heart and Mind. Stockholm: Amfora Future Dialogue AB; 2014.

4. Caligiuri P, De Cieri H, Minbaeva D, et al. International HRM insights for navigating the COVID-19 pandemic: implications for future research and practice. J Int Bus Stud. 2020;51(5):697-713. doi:10.1057/s41267-020-00335-9

5. Abdizadeh M, Khiabani MM. Implementing the spiritual leadership model in the healthcare industry in Iran. Int J Bus Manag. 2014;9 (11):92-101. doi:10.5539/ijbm.v9n11p92

6. Cregård A. Investigating the risks of spiritual leadership. Nonprofit Manag Leadersh. 2017;27(4):533-547. doi:10.1002/nml.21262

7. Brassey J, Kruyt M. How to Demonstrate Calm and Optimism in a Crisis. Organization Practice. New York: McKinsey \& Company; 2020.

8. D' Auria G, de Smet A. Leadership in a Crisis: Responding to the Coronavirus Outbreak and Future Challenges. New York: McKinsey and Company; 2020.

9. Daft RL. The Leadership Experience. 6th ed. TX7, San Diego, CA: Harcourt College Publishers; 2001.

10. Karakas F. Exploring value compasses of leaders in organizations: introducing nine spiritual anchors. J Bus Ethics. 2010;93(1):73-92. doi:10.1007/s10551-010-0627-6

11. Chen CI, Yang CF. The impact of spiritual leadership on organizational citizenship behavior: a multi-sample analysis. J Bus Ethics. 2012;105:107-114.

12. Chen CY, Li CI. Assessing the spiritual leadership effectiveness: the contribution of follower' s self-concept and preliminary tests for moderation of culture and managerial position. Leadersh $Q$. 2013;24(1):240-255. doi:10.1016/j.leaqua.2012.11.004

13. Van Saane J. Personal leadership as form of spirituality. In: Kok JK, Van den Heuvel SC, editors. Leading in a VUCA World: Integrating Leadership, Discernment and Spirituality. Springer; 2019:43-57.

14. Dhiman S, Marques J. Spirituality and Sustainability. Cham: Springer; 2016.

15. Jeon KS, Passmore DL, Lee C, et al. Spiritual leadership: a Validation Study in a Korean context. J Manag Spiritual Relig. 2013;10(4):342-357. doi:10.1080/14766086.2013.801026

16. Ritter RA. Infusing traditional business systems with spiritual wisdom: how mindfulness improves organizational effectiveness Graziadio Bus Rep. 2014;17(3).

17. Chen CY, Yang CY, Li CI. Spiritual leadership, follower mediators, and organizational outcomes: evidence from three industries across two major Chinese societies. J Appl Soc Psychol. 2012;42 (4):890-938. doi:10.1111/j.1559-1816.2011.00834.x

18. Jeon KS, Choi BK. A multidimensional analysis of spiritual leadership, affective commitment and employees' creativity in South Korea. Leadersh Organ Dev. 2020;41(8):1035-1052. doi:10.1108/ LODJ-08-2019-0352

19. Wahid NKA, Mustamil NM. Ways to maximize the triple bottom line of the telecommunication industry in Malaysia the potentials of spiritual well-being through spiritual leadership. J Organ Chang Manag. 2017;30(2):263-280. doi:10.1108/JOCM-07-2015-0105

20. Baykal E. Spiritual leadership in collectivist cultures: Turkey example. In: Mishra D, editor. Science and Spirituality for a Sustainable World. Hershey PA: IGI Global; 2019:44-69.

21. Oh J, Wang J. Spiritual leadership: current status and agenda for future research and practice. J Manag Spiritual Relig. 2020;17 (3):223-248. doi:10.1080/14766086.2020.1728568

22. Novikow V. Spiritual leadership in collectivist and individualist cultures. Emerging Leadersh J. 2017;10(1):1-29.

23. Egel E, Fry L. Spiritual leadership as a model for islamic leadership. Public Integrity. 2016;19(1):77-95. doi:10.1080/10999922.2016.12 00411
24. Farh JL, Hackett RD, Liang J. Individual-level cultural values as moderators of perceived organizational support-employee outcome relationships in China: comparing the effects of power distance and traditionality. Acad Manage J. 2007;50(3):715-729. doi:10.5465/ amj.2007.25530866

25. Alves JC, Manz CC, Butterfield DA, et al. Developing leadership theory in Asia: th e role of Chinese philosophy. Int J Leadersh Stud. 2005;1(1):3-27.

26. Burns JM. Leadership. Leadership. 2005;1:11-12. doi:10.1177/ 1742715005049347

27. Xing YA. Daoism reflection on sea-like leadership and enlightened thinking. Manag Organ Rev. 2016;12(4):807-810. doi:10.1017/ mor.2016.48

28. RGOB (Royal Government of Bhutan). Enhancing Happiness and Sustainable Development Through Partnerships; Joint Task Force (JTF) for the 14th RTM Royal Government of Bhutan and United Nations System in Bhutan. Thimphu: RGOB; 2019.

29. Munro L. Where did Bhutan's gross national happiness come from? The origins of an invented tradition. Asian Aff. 2016;47:71-92. doi:10.1080/03068374.2015.1128681

30. Allison EA. The reincarnation of waste: a Case Study of spiritual ecology activism for household solid waste management. Samdrup Jongkhar Initiative Rural Bhutan Religion. 2019;10:514.

31. Love MS. Security in an insecure world: an examination of individualism-collectivism and psychological sense of community at work. Career Dev Int. 2007;12(3):304-320. doi:10.1108/1362043 0710745917

32. Prakke D. The buddhist truth of happiness spirituality and development - the case of governance in Bhutan. 2005 [digital image]; 2005. Available from: http://www.dspace.cam.ac.uk/handle/1810/227037. Accessed June 11, 2021.

33. Parker RS, Haytko DL, Hermans CM. Individualism and collectivism: reconsidering old assumptions. J Int Bus Res. 2009;8 (1):127-139.

34. Fry LW. Toward a theory of spiritual leadership. Leadersh $Q$. 2003;14(6):693-727. doi:10.1016/j.leaqua.2003.09.001

35. Fry LW, Latham JR, Clinebell SK, et al. Spiritual leadership as a model for performance excellence: a Study of Baldrige Award Recipients. J Manag Spiritual Relig. 2017;14(1):22-47. doi:10.10 80/14766086.2016.1202130

36. Yang F, Liu J, Wang Z, et al. Feeling energized: a multilevel model of spiritual leadership, leader integrity, relational energy, and job performance. J Bus Ethics. 2019;158(4):983-997. doi:10.1007/ s10551-017-3713-1

37. Sharma RR. Evolving a model of sustainable leadership: an ex-post facto research. Vision J Bus Perspect. 2019;23(2):152-169. doi:10. 1177/0972262919840216

38. Stam D, Lord RG, van Knippenberg D, et al. An image of who we might become: vision communication, possible selves, and vision pursuit. Organ Sci. 2014;25(4):1172-1194. doi:10.1287/orsc.2013.0 891

39. Van Knippenberg D, Stam D. Visionary leadership. In: Day DV, editor. The Oxford Handbook of Leadership and Organizations. New York: Oxford University Press; 2014:241-259.

40. Berson Y, Waldman DA, Pearce CL, et al. Enhancing our understanding of vision in organizations: toward an integration of leader and follower processes. Organ Psychol Rev. 2016;6(2):171-191. doi:10.1177/2041386615583736

41. Hybels B. Courageous Leadership. Zondervan: Grand Rapids; 2002.

42. Afsar B, Badir Y, Kiani US. Linking spiritual leadership and employee pro-environmental behavior: the influence of workplace spirituality, intrinsic motivation, and environmental passion. J Environ Psychol. 2016;45:79-88. doi:10.1016/j.jenvp.2015.11.011

43. Parameshwar S. Spiritual leadership through ego-transcendence: exceptional responses to challenging circumstances. Leadersh $Q$. 2005;16(5):689-722. doi:10.1016/j.leaqua.2005.07.004 
44. Venus M, Stam DA, van Knippenberg D, et al. Leader emotion as a catalyst of effective leader communication of visions, value-laden messages, and goals. Organ Behav Hum Decis Process. 2013;122 (1):53-68. doi:10.1016/j.obhdp.2013.03.009

45. Fry LW, Slocum J. Maximizing the triple bottom line through spiritual leadership. Organ Dyn. 2008;37(1):86-96. doi:10.1016/j. orgdyn.2007.11.004

46. Wang M, Guo $\mathrm{T}$, Ni $\mathrm{Y}$, et al. The effect of spiritual leadership on employee effectiveness: an intrinsic motivation perspective. Front Psychol. 2019;9:1-11. doi:10.3389/fpsyg.2018. 02627

47. Den Hartog DN, House RJ, Hanges PJ, et al. Culture specific and cross-culturally generalizable implicit leadership theories: are attributes of charismatic/transformational leadership universally endorsed? Leadersh Q. 1999;10(2):219-256. doi:10.1016/S10489843(99)00018-1

48. Taras V, Kirkman BL, Steel P, et al. Examining the impact of culture's consequences: a three-decade, multi-level, meta-analytic review of hofstede's cultural value dimensions. J Appl Psychol. 2010;95(3):405-439. doi:10.1037/a0018938

49. Wasti SA, Tan HH, Brower HH, et al. Cross-cultural measurement of supervisor trustworthiness: an assessment of measurement invariance across three cultures. Leadersh Q. 2007;18(5):477-489. doi:10.1016/ j.leaqua.2007.07.004

50. Karadag E. The Moderation of National Culture Regarding the Effect of Spiritual Leadership on Organizational Commitment and Productivity: A Cross-Cultural Meta-Analysis. Galatasaray University Journal of Communication. 2016;25:233-260.

51. Triandis HC. Individualism and Collectivism. Boulder, CO: Westview Press; 1995.

52. Triandis HC, Gelfand MJ. Converging measurement of horizontal and vertical individualism and collectivism. $J$ Pers Soc Psychol. 1998;74(1):118-128. doi:10.1037/00223514.74.1.118

53. Fagley NS, Adler MG. Appreciation: a spiritual path to finding value and meaning in the workplace. J Manag Spiritual Relig. 2012;9 (2):167-187. doi:10.1080/14766086.2012.688621

54. Fry LW. Spiritual leadership. In: Farazmand A, editor. Global Encyclopedia of Public Administration, Public Policy, and Governance. Cham: Springer; 2016:1-6.

55. Praskova A, Hood M, Creed PA, et al. Testing a calling model of psychological career success in Australian young adults: a longitudinal study. J Vocat Behav. 2014;85:125-135. doi:10.1016/ j.jvb.2014.04.004

56. Cardador MT, Dane E, Pratt MG, et al. Linking calling orientations to organizational attachment via organizational instrumentality. J Vocat Behav. 2011;79:367-378. doi:10.1016/j. jvb.2011.03.009

57. Fry LW, Cohen M. Spiritual leadership as a paradigm for organizational transformation and recovery from extended work hours cultures. J Bus Ethics. 2009;84(2):265-278. doi:10.1007/s10551008-9695-2
58. Park J, Sohn Y, Ha Y, et al. South Korean salespersons' calling, job performance and organizational citizenship behavior: the mediating role of occupational self-efficacy. J Career Assess. 2016;24:415-428. doi:10.1177/1069072715599354

59. Xie B, Zhou W, Huang JL, et al. Using goal facilitation theory to explain the relationships between calling and organization-directed citizenship behavior and job satisfaction. $J$ Vocat Behav. 2017;100:78-87. doi:10.1016/j.jvb.2017.03.001

60. Hofstede G. Culture's Consequences. 2nd ed. Beverly Hills, CA: Sage; 2001.

61. Chen MJ, Miller D. West meets East: toward an ambicultural approach to management. Acad Manag Perspect. 2010;24(4):17-24. doi:10.5465/amp.2010.24.4.3651479.a

62. The Code of Ethics for Research Workers. Science ethics committee, the general assembly of the polish academy of sciences; 2016. Available from: https://instytucja.pan.pl/index.php/kodeks-etyki-pracownikanaukowego?jjj=1618504298044. Accessed June 11, 2021.

63. Research Code of Conduct-Foundational Principles. Research policies of Royal University of Bhutan; 2014. Available from: https:// www.rub.edu.bt/images/rub/research/policies/research-book.pdf. Accessed June 11, 2021.

64. Cozby PC, Bates SC. Methods in Behavioral Research. 11th ed. New York, NY: McGraw-Hill; 2012.

65. Gholami R, Sulaiman AB, Ramayah T, et al. Senior managers' perception on green information systems (IS) adoption and environmental performance: results from a field survey. Inf Manag. 2013;50 (7):431-438. doi:10.1016/j.im.2013.01.004

66. Taber SK. The use of cronbach's alpha when developing and reporting research instruments in science education. Res Sci Educ. 2018;48:1273-1296. doi:10.1007/s11165-016-9602-2

67. Qing M, Asif M, Hussain A, et al. Exploring the impact of ethical leadership on job satisfaction and organizational commitment in public sector organizations: the mediating role of psychological empowerment. Rev Manag Sci. 2020;14(6):1405-1432. doi:10.1007/ s11846-019-00340-9

68. Akoglu H. User's guide to correlation coefficients. Turk J Emerg Med. 2018;18(3):91-93. doi:10.1016/j.tjem.2018.08.001

69. Hussain A, Asif M, Jameel A, et al. Promoting OPD patient satisfaction through different healthcare determinants: a Study of Public Sector Hospitals. Int J Environ Res Public Health. 2019;16 (19):3719. doi:10.3390/ijerph16193719

70. Nunnally JC, Bernstein IH. Psychometric Theory. New Delhi: Tata McGraw-Hill Ed; 2010.

71. Fornell C, Larcker DF. Structural equation models with unobservable variables and measurement error: algebra and statistics. J Mark Res. 1981;18(3):382-388. doi:10.1177/002224378101800313

72. Reisinger Y, Mavondo F. Structural equation modeling. J Travel Tour Mark. 2007;21(4):41-71. doi:10.1300/J073v21n04_05

73. Hair JF, Arthur HM, Samouel P, et al. Research Methods for Business. Chichester: John Wiley and Sons; 2007.
Psychology Research and Behavior Management

\section{Publish your work in this journal}

Psychology Research and Behavior Management is an international, peer-reviewed, open access journal focusing on the science of psychology and its application in behavior management to develop improved outcomes in the clinical, educational, sports and business arenas. Specific topics covered in the journal include: Neuroscience, memory and decision making; Behavior modification and management; Clinical applications; Business and sports performance management; Socia and developmental studies; Animal studies. The manuscript management system is completely online and includes a very quick and fair peer-review system, which is all easy to use. Visit http://www. dovepress.com/testimonials.php to read real quotes from published authors. 